\title{
The prevalence of colorectal cancer and survival in patients from the Gampaha District, North Colombo region
}

\author{
Thamara Perera ${ }^{1}$, Ruwan E Wijesuriya', P H R Suraweera'1, Kumudu Wijewardene ${ }^{2}$, Sumudu K \\ Kumarage ${ }^{1}$, M H J Ariyaratne, Kemal I Deen'.
}

\begin{abstract}
Introduction The prevalence and survival of colorectal cancer in Sri Lankans has not been previously reported. We did a retrospective and a prospective survey, in the region of North Colombo, Sri Lanka between 1992 and 2004. The aim was to study cancer burden, sites of colorectal cancer and survival after surgery.

Patients and methods The records of 175 patients with colorectal cancer between 1992 and 1997 in the selected region of were analysed retrospectively. A prospective study was performed in 220 new patients with colorectal cancer between 1996 and 2004. Data evaluated were demographics, tumour stage and survival.

Results Between 1992 and 1997 the crude annual incidence of colorectal cancer was 1.9 per 100000 , which increased over the years. The current national crude annual incidence is 3.2 per 100000 in women and 4.9 in men. Median age at presentation was 60 years with similar prevalence of cancer in men and women. In the entire group, $28 \%$ of cancers were in those less than 50 years old. Survival at 2 and 5 years was $69 \%$ and $52 \%$. The majority of cancer related deaths were within the first 2 years after surgery.

Conclusion The burden of colorectal cancer in Sri Lanka is on the rise. Up to a third of cancers occur in those under 50 years, and the majority of cancers are in the rectum or rectosigmoid region. Flexible sigmoidoscopy offers a useful screening tool.
\end{abstract}

\section{Introduction}

Colorectal cancer is now the third most frequently reported cancer world-wide [1-3]. This cancer has shown an increase in incidence in regions where previously, the incidence of colorectal cancer was considered low [4]. Unlike in the west, where colorectal cancer has shown a predominance of right colon cancers, the observed incidence of colorectal cancer in developing countries is known to be chiefly in the left colon. The aim of this study was to determine the pattern of colorectal cancer in the Gampaha District of North Colombo, Sri Lanka, with an estimated population of 1.56 million people at the time of study [5], and to evaluate survival after surgery for colorectal cancer in a cohort of patients.

\section{Patients and methods}

Between 1992 and 1997, the medical records of all patients with histology proven colorectal cancer presenting to 4 regional hospitals and a regional teaching centre were reviewed in phase I of this study. The following demographic data obtained were entered into a database; age at presentation, gender, site of index cancer, the presence of synchronous polyps or cancer, stage of cancer (Duke's and TNM [1]).

Because data on survival in this group of patients in retrospective review was not complete, a prospective study of all patients with colorectal cancer presenting only to the University Surgical Unit was commenced in January 1996 and data analysed in April 2004. This constituted phase II of the study. All patients were followed up in the clinic at 3-month intervals for the first 2 years and at 6month intervals up to 5 years. Thereafter follow up was annually up to 10 years after surgery. Survival was assessed by Kaplan Meier life-table analysis using SPSS v.10.0 for Windows. Approval for this study was granted by the Ethics Committee of the University of Kelaniya.

\section{Results}

\section{Colorectal cancer incidence}

The crude incidence of colorectal cancer in the Gampaha District, North Colombo was calculated from phase I of the study. A total of 175 cases were reported in this district between 1992 and 1997 giving a crude annual incidence of 1.9 per 100000 population. 220 new cases of colorectal cancer were treated at the North Colombo Teaching Hospital and provided data for phase II which aimed to assess 5 year survival. The number of new cases recorded annually had increased over the periods under review in both groups of patients (table 1).

\section{Demography}

In the retrospective review (phase I) the median age (range) at presentation was 60 (9-87) years, and presentation in the prospective series (phase II) was also 60 years (15-88). The age specific cancer prevalence in both series is depicted in table $2.28 \%$ of cancers were in patients less than 50 years in both subsets $(49 / 175$

${ }^{1}$ Department of Surgery, Faculty of Medicine, University of Kelaniya, Ragama, and ${ }^{2}$ Department of Community Medicine, University of Sri Jayawardenepura Nugegoda, Sri Lanka.

Correspondence: KID, e-mail <radihan@mail.ewisl.net>. Conflicts of interest: none declared. 
Table 1. Annual colorectal cancer burden

\begin{tabular}{cccc}
\hline $\begin{array}{c}\text { Annual colorectal cancer burden in } \\
\text { the Gampaha District, North } \\
\text { Colombo, Sri Lanka } \\
\text { (phase I) } \\
n=175\end{array}$ & $\begin{array}{c}\text { Annual colorectal cancer burden in a } \\
\text { tertiary care referral centre at North } \\
\text { Colombo Teaching Hospital } \\
\text { (phase II) } \\
n=220\end{array}$ \\
\hline Year & Number of patients & Year & Number of patients \\
\hline 1992 & 22 & 1996 & 4 \\
1993 & 27 & 1997 & 5 \\
1994 & 22 & 1998 & 27 \\
1995 & 26 & 1999 & 19 \\
1996 & 32 & 2000 & 31 \\
1997 & 46 & 2001 & 34 \\
& & 2002 & 38 \\
& & 2003 & 34 \\
& & 2004 & 44 \\
\hline Total & $\mathbf{1 7 5}$ & & $\mathbf{2 2 0}$ \\
\hline
\end{tabular}

Table 2. Age specific colorectal cancer burden

\begin{tabular}{|c|c|c|}
\hline & $\begin{array}{l}\text { Gampaha District, } \\
\text { North Colombo } \\
\text { (phase I) }\end{array}$ & $\begin{array}{c}\text { Professorial Surgical Unit, } \\
\text { North Colombo Teaching Hospitat } \\
\text { (phase II) }\end{array}$ \\
\hline Age group & Number of patients (\%) & Number of patients (\%) \\
\hline$<20$ years & $4 \quad(2 \%)$ & $3 \quad(1 \%)$ \\
\hline $21-30$ years & $5 \quad(3 \%)$ & $8 \quad(4 \%)$ \\
\hline $31-40$ years & $14 \quad(8 \%)$ & $18 \quad(8 \%)$ \\
\hline $41-50$ years & $26(15 \%)$ & $31 \quad(14 \%)$ \\
\hline$>50$ years & $126(72 \%)$ & $160(73 \%)$ \\
\hline Total & 175 & 220 \\
\hline
\end{tabular}

phase I cohort and 60/220 phase II cohort). Colorectal cancer occurred in similar numbers of men and women; phase I study male:female $=94(54 \%): 81(46 \%)$ : phase II male:female $=109(49.5 \%): 111(50.5 \%)$.

The majority of cancers were found either in the rectum or rectosigmoid junction in both cohorts; phase I 111/175 (64\%); phase II 176/220 (80\%).

\section{Tumour stage}

Complete tumour staging (Duke's and TNM [1]) was available for 126 patients in phase I and 201 patients in phase II. Combined evaluation of 327 patients revealed Duke's A and B lesions in 175 (53.5\%) patients. Tumour stage is shown in tables 3 and 4.

\section{Treatment}

Of 220 patients analysed prospectively 6 patients were managed without operation either due to advanced disease or high surgical risk. 214 patients had surgery (table 5). Perioperative mortality was 5\% (11 of 220) and was due to myocardial infarction (5), anastomotic leakage and multi-organ failure (3) and bronchopneumonia (3).

\section{Survival}

Survival analysis was possible only in phase II of the study. Eighty of 220 patients (36\%) analysed prospectively had died during follow up (median 24 months: range 1-94 months). The majority of deaths occurred during the first 24 months. Survival at 2 years and at 5 years was $69 \%$ and $52 \%$ (figure 1 ). 
Table 3. Stage of colorectal cancer using Duke's system

\begin{tabular}{crcr}
\hline Duke's stage & $\begin{array}{c}\text { Retrospective series/phase I } \\
\text { number }(\%)\end{array}$ & $\begin{array}{c}\text { Prospective series/phase II } \\
\text { number }(\%)\end{array}$ \\
\hline A & 3 & $(2.3)$ & $33(16.4)$ \\
B & 59 & $(46.8)$ & $80(39.8)$ \\
C & 45 & $(35.7)$ & $57(28.3)$ \\
D & 19 & $(15 \%)$ & $31 \quad(15.4)$ \\
\hline Total & $\mathbf{1 2 6}$ & $\mathbf{2 0 1}$ \\
\hline
\end{tabular}

Table 4. T stage (wall stage) of colorectal cancer

\begin{tabular}{ccc}
\hline Tumour stage (T) & $\begin{array}{c}\text { Retrospective series/phase I } \\
\text { number (\%) }\end{array}$ & $\begin{array}{c}\text { Prospective series/phase II } \\
\text { number (\%) }\end{array}$ \\
\hline $\mathrm{T} 1$ & $\mathbf{3} 33(26)$ & $12(6.1)$ \\
$\mathrm{T} 2$ & $\mathbf{3} 93(74)$ & $36(18.5)$ \\
$\mathrm{T} 3$ & $109(56.2)$ \\
$\mathrm{T} 4$ & $\mathbf{3}$ & $37(19.0)$ \\
\hline Total & $\mathbf{1 2 6}$ & $\mathbf{1 9 4}$ \\
\hline
\end{tabular}

Table 5. Type and number of operations performed in patients with colorectal cancer

\begin{tabular}{lrc}
\hline Type of operation & \multicolumn{3}{c}{ Number } & $(\%)$ \\
\hline Hemicolectomy & 36 & $(16.4 \%)$ \\
Sigmoid colectomy & 29 & $(13.1 \%)$ \\
Subtotal colectomy & 13 & $(5.9 \%)$ \\
Restorative proctocolectomy & 6 & $(2.7 \%)$ \\
Anterior resection & 100 & $(45.4 \%)$ \\
Abdomino-perineal excision & 12 & $(5.4 \%)$ \\
Hartmann's operation & 13 & $(5.9 \%)$ \\
Paul Mickulicz operation & 1 & $(0.4 \%)$ \\
Local excision & 5 & $(2.27 \%)$ \\
No surgery & 6 & $(2.72 \%)$ \\
\hline Total & $\mathbf{2 2 0}$ & \\
\hline
\end{tabular}

Table 6. Colorectal cancer stage in patients under $\mathbf{5 0}$ years of age Stage of young cancers; $n=60^{*}$

\begin{tabular}{cccccccc}
\hline \multicolumn{2}{c}{ Tumour Stage (T) } & \multicolumn{2}{c}{ Nodal Stage $(N)$} & \multicolumn{2}{c}{ Metastasis $(M)$} & \multicolumn{2}{c}{ Duke's Stage } \\
Stage & Cases (\%) & Stage Cases $(\%)$ & Stage & Cases $(\%)$ & Stage & Cases $(\%)$ \\
\hline T1 & $2(3.3 \%)$ & N0 & $28(46.6 \%)$ & M0 & $52(87 \%)$ & A & $7(11.6 \%)$ \\
T2 & $11(18.3 \%)$ & N1 & $11(18.3 \%)$ & M1 & $3(5 \%)$ & B & $22(36.6 \%)$ \\
T3 & $31(51.6 \%)$ & N2 & $16(26.6 \%)$ & & & C & $22(36.6 \%)$ \\
T4 & $11(18.3)$ & & & & & D & $4(6.6 \%)$ \\
\hline
\end{tabular}

* Stage not available $=05(8.3 \%)$ 


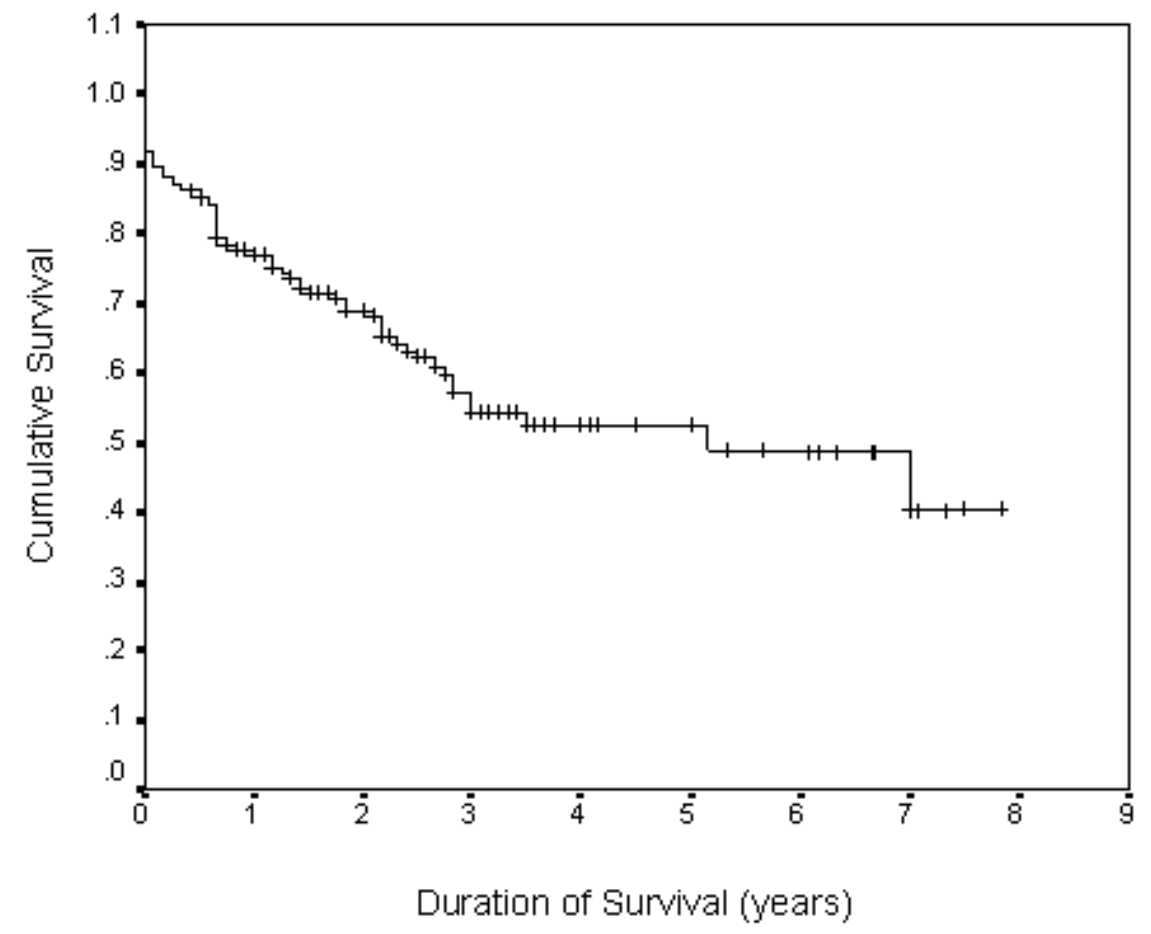

Figure 1. Overall survival following surgery for colorectal cancer in 220 patients (life table analysis)

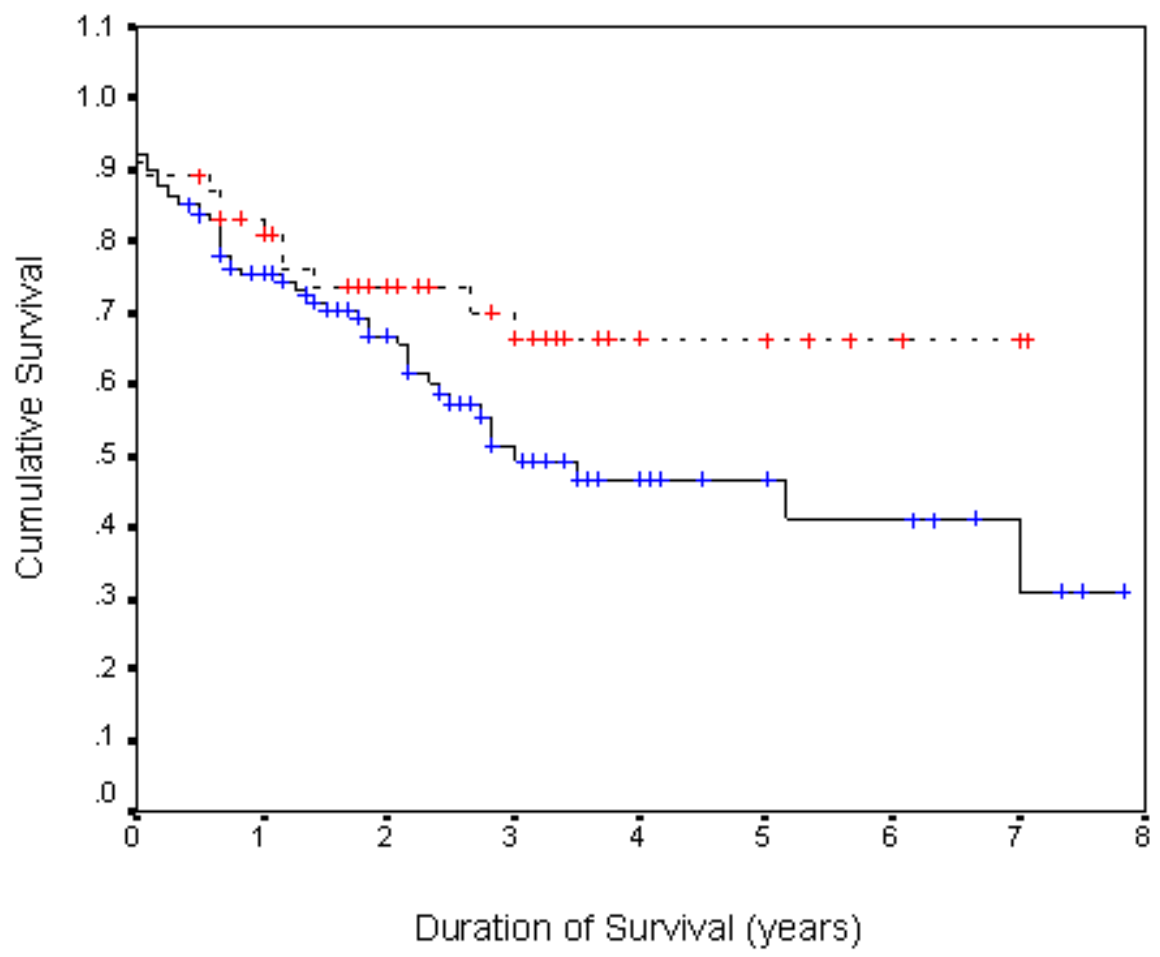

Figure 2. Survival in young ( $<50$ years) patients versus older patients (life table analysis) 


\section{Cancer in patients $<50$ years}

60 patients $(27.3 \%$; 30 male: 30 female) in the prospective series were under the age of 50 years. The median age (range) at the time of diagnosis was 42 years (16-49). The majority (69\%) presented with rectal bleeding, and the remainder presented with abdominal pain (36\%), anaemia or unexplained loss of weight. Only one patient presented with large bowel obstruction. Altogether, 12 (20\%) patients had a family history of cancer of which 4 (6.7\%) were site specific, and the rest were extra-colonic.

In $48(80 \%)$ young patients, cancer was found in the left colon compared with $12(20 \%)$ who had right-sided cancer. Two patients with rectal cancers had familial adenomatous polyposis. Complete tumour staging was available in 55 patients (table 4). Duke's staging revealed that 7 (11.6\%) were Duke's A, 22 (36.6\%) Duke's B, and 26 (43\%) Duke's C or D. Survival in young patients in the first 2 years was $73 \%$ versus $66 \%$ in older patients and appeared to plateau between 2 and 5 years, whereas in older patients, survival continued to decline annually up to 5 years after operation (figure 2).

\section{Discussion}

This study has shown an increase in the incidence of colorectal cancer in the defined population in North Colombo. The upward trend has been also observed by reported increased incidence of crude rates of colorectal cancer in women (3.2/100 000) and in men (4.9/100 000) by the WHO [6] in the year 2000.

A significant finding in our study is of colorectal cancer in $28 \%$ of patients less than 50 years of age, in the majority of whom the Amsterdam criteria [7] were not fulfilled. Some patients were in their teens and had no associated polyposis - a feature that is not common in western countries.
Furthermore, unlike in the west, between $64 \%$ and $80 \%$ of colon and rectal cancers presented with an index cancer in either the rectum or rectosigmoid region, so that rectal examination and flexible sigmoidoscopy will provide a useful method of screening for colorectal cancer.

Our perioperative 30-day mortality after surgery for colorectal cancer was $5 \%$, and 2-year and 5 -year survival after surgery for colorectal cancer was $69 \%$ and $52 \%$. These are similar to data from the west before screening was introduced.

\section{References}

1. Bennett DH, Hardcastle JD. Early diagnosis and screening. In: Williams NS (ed) Colorectal cancer. London. Churchill Livingstone. 1996 ;21-7.

2. Boardman L, Karnes WE Jr. Epidemiology and etiology of colorectal cancer. In: Nicholls RJ, Dozois RR (eds) Surgery of the colon and rectum. London. Churchill Livingstone, 1st edition. 1997;1835-48.

3. Chu KC, Kramer BS, Smart CR. Analysis of the role of cancer prevention and control measures in reducing cancer mortality. Journal of the National Cancer Institute 1991; 83: 1636-43.

4. Haenzel W, Core P. Cancer of the colon and rectum and adenomatous polyps. A review of epidemiologic findings. Cancer 1971; 28: 14-24.

5. Handbook on population census statistics 1993. Department of Census and Statistics. Government Press, Colombo, Sri Lanka.

6. WHO. Globocan 2000; Cancer incidence, mortality and prevalence worldwide (on CD-ROM) accessed on 21 September, 2006.

7. Vasen HFA, Mecklin JP, Merakhan P, Lynch HT. The international collaborative group on hereditary nonpolyposis colorectal cancer. Diseases of the Colon and Rectum 1991; 34: 424-5. 